\title{
Rancang Bangun Detector Kebakaran Panel Listrik Berbasis Mikrocontroller Atmega 328 Pada Kapal Penangkap Ikan
}

\author{
Basino $^{1 \#}$, Pungkas Prayitno ${ }^{2}$, Sobri $^{1}$, J. Preston Siahaan $^{3}$, Muhamad Bisri Mustofa ${ }^{1}$ \\ ${ }^{\text {I }}$ politeknik Ahli Usaha Perikanan \\ Jl. AUP Pasar Minggu, Jakarta Selatan \\ E-mail ${ }^{1}$ : basinomusyaffa@gmail.com \\ sobriaira2016@gmail.com \\ ${ }^{2}$ Universitas Sutomo Serang \\ Jl. Raya Serang-Jakarta Kel. Walantaka Kota Serang Provinsi Banten \\ E-mail ${ }^{2}$ : pungkasprayitno@gmail.com \\ ${ }^{3}$ Politeknik KP Dumai \\ Jl. Wan Amir, No. 1, Kelurahan Pangkalan Sesai, Kecamatan Dumai Barat, Kota Dumai \\ E-mail ${ }^{3}$ : preston_siahaan@yahoo.com
}

Received: 22 August 2021; Revised: 02 October 2021; Accepted: 30 December 2021

DOI: http://dx.doi.org/10.37905/aksara.8.1.697-712.2022

\begin{abstract}
ABSTRAK
Tujuan dari penelitian ini adalah untuk mengantisipasi terjadinya kebakaran yang sangat besar dengan memantau kondisi panel listrik yang ada di kapal. Penelitian ini menggunakan kontrol listrik miniatur berukuran tinggi $35,5 \mathrm{~cm}$, panjang $27 \mathrm{~cm}$ dan lebar 9. Perancangan fire detector panel listrik berbasis mikrokontroler tipe 328 digunakan untuk memonitor keberadaan benda api dan suhu yang melebihi batas maksimal dengan menggunakan sensor suhu DHT22 dan sensor nyala api yang ada pada panel listrik di kapal. Hasil pembacaan sensor akan diproses menggunakan mikrokontroler Atmega 328 yang ditampilkan dalam aplikasi IDE, dalam bentuk data deteksi kebakaran, pembacaan suhu dan kondisi pada panel. Ketika sensor mendeteksi api dan suhu melebihi batas buzzer maksimum dan LED akan menyala untuk menginformasikan alarm dan ketika sensor sensor tidak mendeteksi objek kebakaran atau suhu melebihi batas, buzzer dan LED akan mati.
\end{abstract}

Kata kunci : kebakaran, flame sensor, DHT22, Microcontroller Atmega328

\section{ABSTRACT}

The aim of this research is to anticipate the occurrence of a very large fire by monitoring the condition of the electrical panels that exist in the ship. This Study uses a miniature electric control measuring $35.5 \mathrm{~cm}$ high, $27 \mathrm{~cm}$ long and 9 wide. Design of fire detector electric panel based microcontroller tipe 328 used to monitor the the presence of fire objects and temperatures that exceed the maximum limit by using the DHT22 temperature sensor and flame sensor which is on the electric panel in the ship. The results of sensor readings will be processed using microcontroller Atmega 328 displayed in the IDE application, In the form of fire detection data, temperature and condition readings on 
the panel. When the sensor detects fire and the temperature exceeds the maximum buzzer limit and the LED will light to infrom the alarm and when the sensor sensor does not detect the object fire or the temperature exceeds the limit, the buzzer and LED will turn off.

Keywords :Fire, Flame Sensor, DHT22, Microcontroller Atmega328

\section{PENDAHULUAN}

Bahaya kebakaran merupakan bahaya yang mempunyai kemunginan besar terjadi di segala sektor kehidupan. Kebakaran akan membawa banyak kerugian baik moril maupun materiil. Untuk itu upaya-upaya penanggulangan terjadinya kebakaran yang mampu mendeteksi gejala-gejala dini kebakaran termasuk salah satunya pemasangan detektor kebakaran (Marselinus et al, 2012). Arduino adalah kit elektronik atau board rangkaian elekrtonik open source yang didalamnya terdapat komponen utama, yaitu sebuah chip mikrokontroller dengan jenis AVR (Alf and Vegard's Risc Processor) dari perusahaan Atmel (Lulu F., et al, 2018 dan Setyowinoto et al, 2017). Penelitian dengan memanfaatkan Arduino sebagai mikrokontroller pendeteksi kebakaran telah banyak dilakukan. Fina S., et al 2013 dan Mifza F., et al, 2017 membuat suatu alat pengaman model alarm sistem detektor gas LPG yang bekerja secara otomatis sehingga dapat membuang gas jika terjadi kebocoran berbasis arduino. Pada penelitian lain, asap rokok menjadi input sistem kontrol dengan sensor type MQ guna menekan angka perokok pada area-area tertentu ( Nurfiana et al, 2017 dan M. Subchan M., et al, 2016). Arduino juga dipakai sebagai basis detektor polutan udara CO dan CO2 (Constantien, et al, 2019 dan Dwi Ika, 2018) dimana disimpulkan bahwa turunnya kadar emisi akan diiringi dengan turunnya temperatur udara dan kelembaban udara akan meningkat. Api, asap dan kenaikan suhu merupakan input yang dapat dipakai pada detektor kebakaran. Dani Sasmoko, et al 2017 mengamati bahwa sensor api mampu mendeteksi kebradaan api namun kemampuannya terbatasi oleh luas area, sedangkan sensor asap dipengaruhi oleh arah angin ke sensor. Pada penelitian lain oleh Sofyan, et al, 2019 mengamati bahwa jangkauan sensor asap bertambah dengan semakin banyaknya asap yang terdeteksi. Lilik , et al, 2017 dalam penelitiannya menggunakan sensor gas dengan $\geq 3500$ PPM dan sensor cahaya $\geq 12$ lux.

Energi listrik yang sangat kita butuhkan dalam kehidupan sehari hari juga menyimpan potensi kebakaran. Bahaya kebakaran akibat listrik dapat disebabkan baik oleh faktor teknis maupun faktor non-teknis. Salah satu bagian yang mempunyai kemungkinan besar terjadi bahaya kebakaran adalah box panel listrik. Pada instalasi listrik, box panel listrik memiliki peranan penting dimana didalam box panel listrik ini terdapat kabel-kabe, MCB, dan peralatan listrik lainnya yang berkaitan dengan pengontrolan jaringan listrik. Kejadian kebakaran salah satu disebabkan oleh konsleting listrik yang terjadi akibat alat yang digunakan sebagai penghantar memiliki keamanan yang kurang baik sehingga mengakibatkan terjadinya percikan api yang dapat menyebabkan kebakaran. (Refky A., et al, 2015). menurut Budi setyo, 2014, penyebab kebakaran tertinggi diakibatkan oleh korsleting listrik pada peralatan instalasi listrik terutama pada pemasangan instalasi listrik yang tidak sesuai standar dan instalasi listrik yang sudah berumur tua. Selain itu penggunaan, pemasangan dan perlakuan pada 
peralatan listrik yang kurang baik juga menyebabkan korsleting listrik. selain peraturan untuk instalasi listrik dan penggunaan peralatan canggih, harus didukung dengan menerapkan model sistem intalasi listrik dengan pengaman yang komprehensip (Susiono, 2010). Guna meminimalisir bahaya kebakaran pada sebuah panel listrik, maka salah satu usaha yang perlu dilakukan adalah menambahkan sebuah detektor kebakaran panel listrik agar bisa menghindari bahaya kebakaran.

\section{BAHAN DAN METODE}

\section{Bahan untuk pembuatan detector kebakaran panel listrik antara lain :}

1. Software Arduino IDE

Beberapa software Arduino ditulis menggunakan bahasa pemrograman Java termasuk IDE-nya, sehingga ia tidak perlu diinstal seperti software pada umumnya tapi dapat langsung dijalankan selama komputer Anda telah terinstall Java runtime dan menginstal driver terlebih dahulu (Dani, P., 2016)

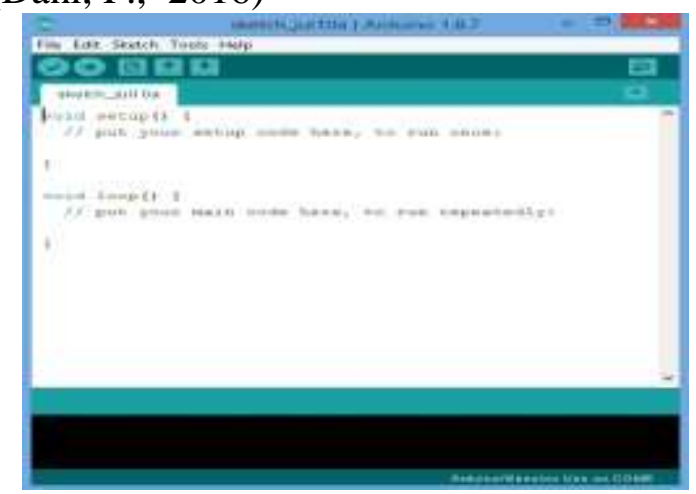

Gambar1. Tampilan software IDE Arduino dengan sebuah sketch.

Figure 1. Display of IDE Arduino sotfware with a sketch.

2. Mikrokontroller Atmega328

Komponen utama di dalam papan Arduino adalah sebuah mikrokontroller 8 bit dengan merk ATmegayang dibuat oleh perusahaan Atmel Corporation. Berbagai papan Arduino menggunakan tipe ATmega yang berbeda-beda tergantung dari spesifikasinya.

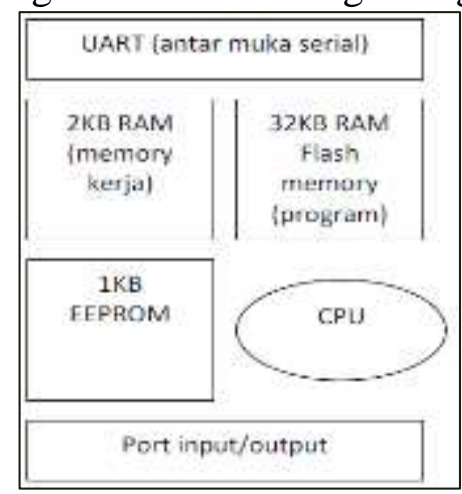

Gambar 2. Diagram blok sederhana dari mikrokontroller

Figure 2. Block diagram of microcontroller

Blok-blok di atas dijelaskan sebagai berikut:

a. Universal Asynchronous ReceiveratauTransmitter (UART) adalah antar muka yang digunakan untuk komunikasi serial seperti pada RS-232, RS-422 dan RS-485.

AKSARA: Jurnal Ilmu Pendidikan Nonformal 
b. 2KB RAM pada memori kerja bersifat volatile (hilang saat daya dimatikan), digunakan oleh variable-variabel di dalam program.

c. 32KB RAM flash memory bersifat non-volatile, digunakan untuk menyimpan program yang dimuat dari komputer. Selain program, flashmemory juga menyimpan bootloader. Bootloader adalah program inisiasi yang ukurannya kecil, dijalankan oleh CPU saat daya dihidupkan. Setelah bootloader selesai dijalankan, berikutnya program di dalam RAM akan dieksekusi.

d. 1KB EEPROM bersifat non-volatile, digunakan untuk menyimpan data yang tidak boleh hilang saat daya dimatikan. Tidak digunakan pada papan Arduino.

e. Central Processing Unit (CPU), bagian dari mikrokontroller untuk menjalankan setiap instruksi dari program.

f. Port input/output, pin-pin untuk menerima data (input) digital atau analog, dan mengeluarkan data (output) digital atau analog.

\section{Sensor Api ( Flame Sensor )}

Sensor api merupakan salah satu alat instrument berupa sensor yang dapat mendeteksi nilai instensitas dan frekuensi api dalam suatu proses pembakaran, dalam hal ini pembakaran dalam boiler pada pembangkit listrik tenaga uap. Sensor api dapat mendeteksi kedua hal tersebut dikarenakan oleh komponenkomponen pendukung dari sensor api tersebut,dapat dilihat pada gambar 4 dibawah ini: Flame sensor mempunyai fungsi sebagai pendeteksi nyala api yang dimana api tersebut memiliki panjang gelombang antara 760nm $-1100 \mathrm{~nm}$. Sensor ini menggunakan infrared sebagai tranduser dalam mensensing kondisi nyala api.

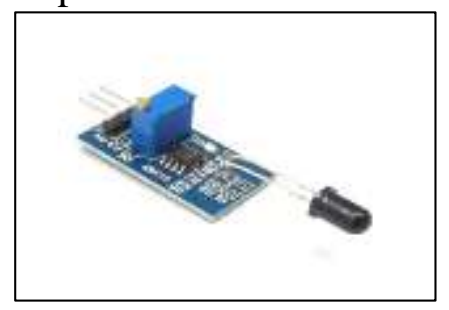

Gambar 3.Sensor Api

Figure 3. Fire Sensor

\section{Sensor Suhu DHT22}

DHT22 adalah sensor digital yang dapat mengukur suhu dan kelembaban udara di sekitarnya. Sensor ini sangat mudah digunakan bersama dengan Arduino. Memiliki tingkat stabilitas yang sangat baik serta fitur kalibrasi yang sangat akurat. Koefisien kalibrasi disimpan dalam OTP program memory, sehingga ketika internal sensor mendeteksi sesuatu, maka module ini menyertakan koefisien tersebut dalam kalkulasinya,DHT22initermasuk sensor yang memiliki kualitas terbaik, dinilai dari respon, pembacaan data yang cepat, dan kemampuan anti-interference. Ukurannya yang kecil, dan dengan transmisi sinyal hingga 20 meter,dengan sepsifikasi: Supply Voltage: $+5 \mathrm{~V}$, Temperature range : $0-50{ }^{\circ} \mathrm{C}$ error of $\pm 2{ }^{\circ} \mathrm{C}, \quad$ Humidity : $20-90 \% \mathrm{RH} \pm 5 \% \mathrm{RH}$ error, dengan sesifikasi digital interfacing system. membuat produk ini cocok digunakan untuk banyak aplikasi-aplikasi pengukuran suhu dan kelembaban. 


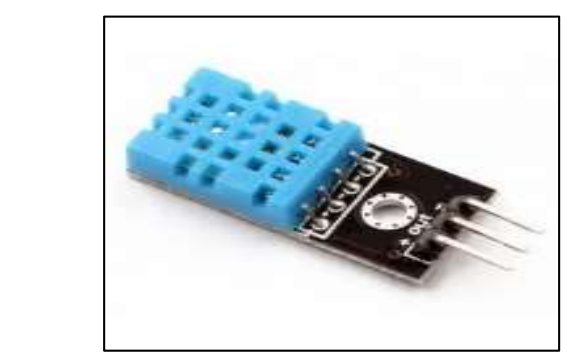

Gambar 4. Sensor Suhu DHT22

Figure 4. Temperature sensor DHT22

\section{Lampu LED}

LED (Light Emitting Diode) adalah jenis dioda yang memancarkan cahaya. Komponen ini biasa digunakan pada lampu senter atau emergency. Seperti halnya dioda yang hanya mengalirkan arus listrik searah, LED juga demikian. Itulah sebabnya pemasangan LED dirangkaian elektrioka harus tidak terbalik.

LED ini dapat digunakan sebagai output saat seorang pengguna membuat sebuah program dan ia membutuhkan sebuah penanda dari jalannya program tersebut. Ini adalah cara yang praktis saat pengguna melakukan uji coba. Umumnya mikrokontroller pada papan Arduino telah memuat sebuah program kecil yang akan menyalakan LED tersebut berkedip-kedip dalam jeda satu detik.

\section{Buzzer}

Buzzer adalah sebuah komponen elektronika yang berfungsi untuk mengubah getaran listrik menjadi getaran suara. Pada dasarnya prinsip kerja buzzer hampir sama dengan loud speaker, jadi buzzer juga terdiri dari kumparan yang terpasang pada diafragma dan kemudian kumparan tersebut dialiri arus sehingga menjadi elektromagnet, kumparan tadi akan tertarik ke dalam atau ke luar, tergantung dari arah arus dan polaritas magnetnya.Buzzer biasa digunakan sebagai indikator bahwa proses telah selesai atau terjadi kesalahan pada sebuah alat (alarm).[4][10]

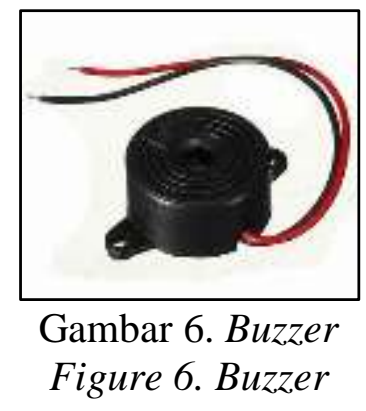

\section{Prinsip Kerja dan Fungsi Rancangan}

Prinsip kerja alat ini yaitu berdasarkan input daripada sensor api dan suhu yang berupa perubahan nilai resistansi analog pada pin keluarannya. Pada pin keluaran ini kemudian disambungkan pada mikrokontroller / pinanalog input arduino yang sebelumnya telah dilakukan pemograman dan disambungkan pada buzzer yang akan digunakan sebagai indikator bahwa proses telah selesai atau terjadi kesalahan pada sebuah alat (alarm) dan 
lampu LED digunakan sebagai indikator bahwa alat tersebut bekerja atau tidak. Komponen tersebut digunakan sebagai output daripada alat tersebut.

Fungsi daripada alat ini adalah untuk mendetaksi adanya api dan suhu yang melampaui batas dan memberi peringatan melalui bunyi daripada buzzer bahwa terjadi adanya konsletinglistrik yang terjadididalambok panel listrik yang adadikapal.

\section{METODE PENELITIAN}

Penelitian ini meliputi tiga kegiatan utama yaitu mendesain alat menggunakan softwareProtenius 8 yang akan digunakan sebagai panduan atau dasar dalam melakukan perakitan (pembuatan) alat pendeteksi kebakaran dikapal, pembuatan alat deteksi kebakaran panel listrik harus sesuai dengan desain yang telat dibuat dan pengujian alat pendeteksi kebakaran ini untuk mengetahui apakah alat yang dibuat dapat berfungsi untuk melakukan pendeteksian api dan suhu dengan baik atau belum. Ditambah dengan Studi Literatur sebagai penunjang bahan pustaka pada penelitian ini.

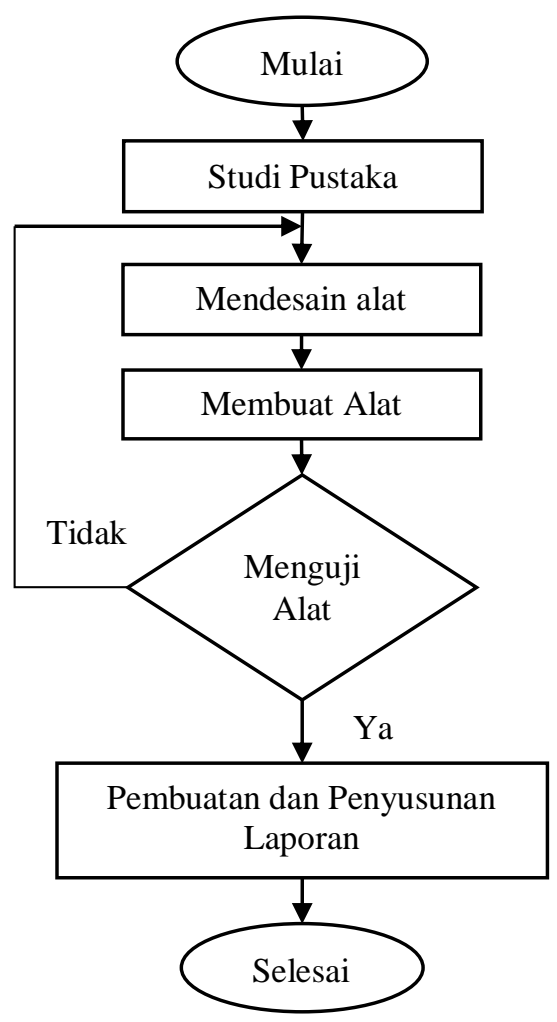

Gambar 7. Diagram alir Rancang Bangun Detector Kebakaran Panel Listrik BerbasisMicrocontroller Atmega328

\section{HASIL DAN BAHASAN}

\section{Desain Alat Deteksi Kebocoran Refrigeran}

Pada tahapan ini melakukan pembuatan desain Rancang Bangun Detector Kebakaran Panel Listrik Berbasis Microcontroller Atmega328 aplikasi (software) 
Protenius 8 yang akan digunakan sebagai dasar dalam melakukan perakitan atau pembuatan Rancangan.

Dimana hasil akhir dari desain alat ini yaitu menghasilkan alat untuk mendeteksi Api dan Suhudidalam box panel listrikdengan merangkai komponen - komponen yang telah persiapkan terlebih dahulu. Berikut ini adalahRancangannya :

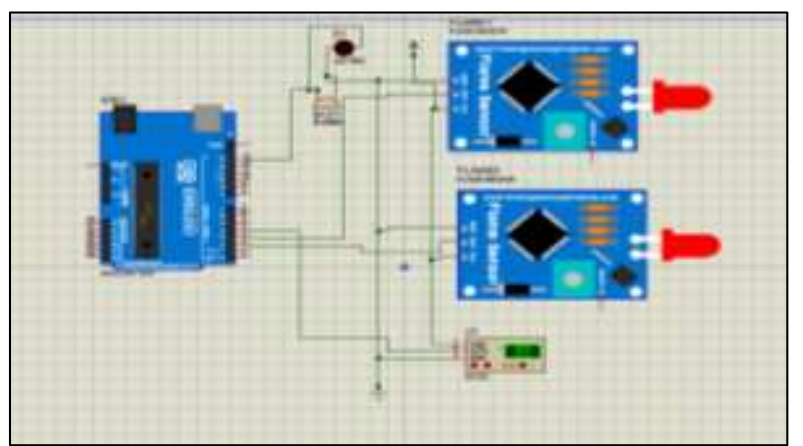

Gambar 8. Rancang Bangun Detector Kebakaran Panel Listrik Berbasis Microcontroller Atmega328

\subsection{Pembuatan Alat Deteksi Kebakaran Panel Listrik}

Pada proses atau tahapan ini adalah lanjutan dari tahapan mendesain alat, dimana komponen - komponen yang telah disiapkan dirakit menjadi sebuah rancangan dan rancangan yang akan dibuat haruslah sesuai dengan yang telah dirancang sebelumnya. Dalam pembuatan alat perlu beberapa hal yang harus dipersiapkan, yaitu :

1. Mempersiapkan komponen - komponen Rancangan (Sensor Api, Sensor Suhu DHT22, mikrokontroller atmega328, Buzzer, Lampu LED dan Kabel Jumper).

2. Box panel listrik atau tempat untuk menempatkan alat yg telah dirangkai menjadi satu.

3. Alat dan bahan lainnya untuk mendukung dalam pembutan alat tersebut (Solder, Timah Solder, Gunting, dll).

Setelah semua siap, selanjutnya dilakukan perakitan alat.

\subsubsection{Instalasi Arduino IDE}

IDE (Integrated Development Environment) yang digunakan dalam pembangunan aplikasi ini adalah IDE arduino versi 1.8.7 yang diinstal kedalam komputer atau laptop, Setelah menginstal software arduino tahap selanjutnya yaitu melakukan pembuatan program (Coding) yang akan diinput kedalam mikrokontroller, pemrogrman tersebut merupakan bagian terpenting untuk membuat Rancangan pendeteksi kebakaran panel listrik karena dalam pemrograman tersebut terdapat pengaturan tingkat sensitivitas sensor terhadapapi dan suhu. Sehingga pemrograman tersebut harus sesuai dengan kebutuhan atau yang diinginkan agar alat tersebut dapat berjalan dengan sempurna. Pemograman didalam software IDE Arduino yaitu ditulis dengan menggunakan Bahasa C.

Setalah melakukan pembuatan program tahapan selanjutnya yaitu mengupload atau memasukkan data program tersebut kedalam mikrokontroller (Banzi, 2008). 


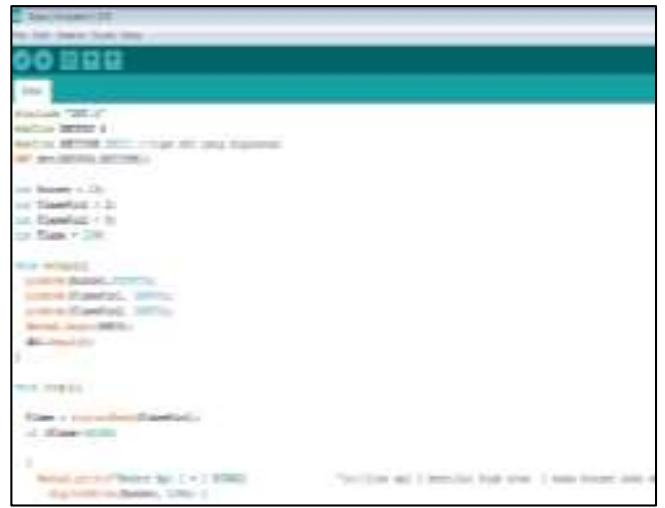

Gambar 9. Sebuah sketch software Arduino IDE

\subsubsection{Perancangan PendeteksiKebakaran Panel secaramenyeluruh}

SistemArduinoUno memiliki14pinI/Odigitaldan6pinI/Oanalog. Pin - pin tersebut dapat digunakan sebagai masukan dari sensor - sensor dan keluaran output untuk mengaktifkan komponen lainnya.[14]

Alat dan bahan yang digunakan atau dibutuhkan dalam perakitan rancanganpendeteksikebakaran panel listrikadalah:

\begin{tabular}{|l|l|}
\hline Sensor Suhu & 6.Mikrokontroller \\
\hline Sensor Api & 7.Buzzer \\
\hline LED & 8.Box panel listrik \\
\hline Kabel jumper & 9.Korek api \\
\hline Cutter & \\
\hline
\end{tabular}

Setelah melakukan perancangan pada tiap - tiap komponen, selanjutnya adalah memasukkan komponen - komponen tersebut kedalam box Panel seperti pada gambar dibawah ini.

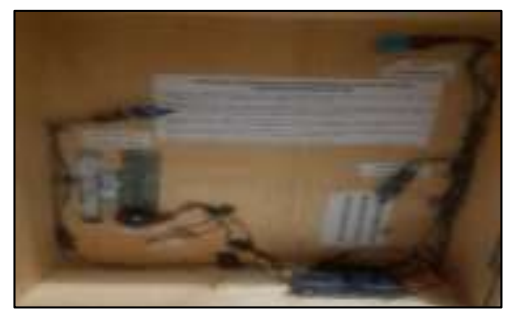

\subsection{Pengujian alat (Testing)}

Gambar 4. Alat deteksi kebakaran yang telah dibuat.

Pengujian terhadap alat ini bertujuan untuk mengetahui apakah alat ini bekerja dengan baik atau tidak, sesuai dengan rancangan yang dikehendaki atau belum.

Pengujianyangdilakukan padabab iniantaralain:

1. Pengujian Sensor dan Buzzer denganSistem Arduiono.

2. Pengujian RangkaianPendeteksiKebakaran Panel Listrik. 
Simulasi cara untuk menguji (Testing) alat tersebut yaitu dengan menggunakan media (Api) yang aman dan tidak mengakibatkan kerugian - kerugian. Media tersebut adalah KorekApi.

\subsubsection{Pengujian Sensor ApidenganSistem microcontroller}

Pengujian sensor api dilakukan dengan melihat perubahan jumlah nilai sinyal digital ketika High dan Low melalui serial monitor pada Arduino Atmega 328. Pada sensor api menggunakan output sinyal digital bernilai 1 atau 0, on atau off, High atau Low. Ketika sensor api mendeteksi adanya obyek api yang dideteksi sensor api akan mengirim sinyal digital ke Arduino dan selanjutnya Arduino akan menerima sinyal tersebut dan menampilkan output dari pembacaan sensor api melalui serial monitor. Kemudian ketika sensor api tidak mendeteksi adanya obyek api, sensor api akan tetap mengirim sinyal digital ke Arduino, Arduino akan tetap memproses dan menampilkan output sinyal digital melalui serial monitor. Sinyal digital yang ditampilkan bernilai 1 dan 0 , dimana nilai 1 menandakan sensor api dalam kondisi tidak mendeteksi adanya obyek

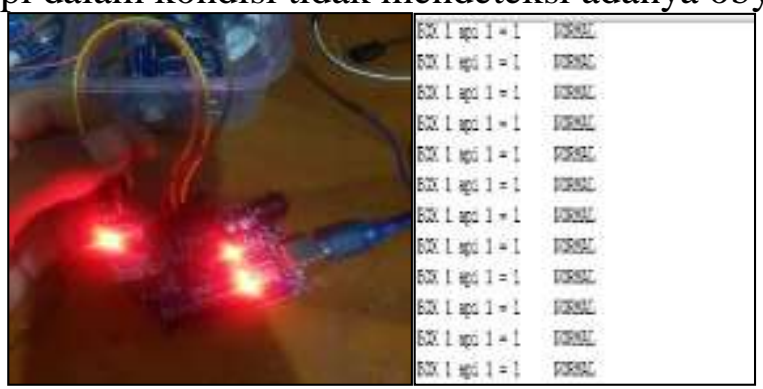

Gambar 11.Pengujian Sensor Api dalam kondisi Normal

Pengujian sensor api dalam kondisi normal (Gambar 11), kondisi LED indikator pada sensor api menyala sedangkan LED indikator D0 padam. serial monitor menampilkan nilai digital 1 dengan status normal.

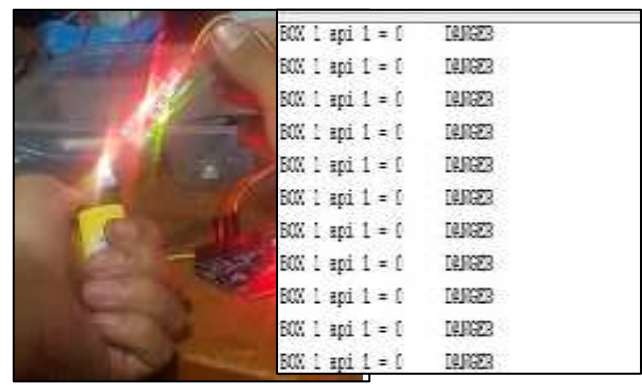

Gambar 12. PengujianKondisi Danger

Gambar 12 menunjukkan pengujian sensor api dalam kondisi danger, kondisi tersebut menandakan sensor api mendeteksi adanya api yang berada disekitar sensor, LED indikator power akan hidup menandakan sensor aktif dan LED indikator D0 hidup menandakan sensor api mendeteksi adanya api. Serial monitor menampilkan nilai digital 0 dengan status danger.

Tabel 1. Hasil pengujian sensor api 


\begin{tabular}{|c|c|c|c|c|c|}
\hline \multirow{2}{*}{ No } & \multirow{2}{*}{ Kondisi Api pada box Panel } & \multicolumn{2}{c|}{ Buzzer dan LED } & \multicolumn{2}{c|}{ Status Sensor Api } \\
\cline { 3 - 6 } & & Kondisi & Waktu & nilai & Status \\
\hline 1 & padam & padam & 0 detik & 1 & normal \\
\hline 2 & padam & padam & 0 detik & 1 & normal \\
\hline 3 & padam & padam & 0 detik & 1 & normal \\
\hline 4 & padam & padam & 0 detik & 1 & normal \\
\hline 5 & padam & padam & 0 detik & 1 & normal \\
\hline 6 & padam & padam & 0 detik & 1 & normal \\
\hline 7 & api 2 detik & menyala & 2 detik & 0 & danger \\
\hline 8 & api 3 detik & menyala & 3 detik & 0 & danger \\
\hline 9 & api 4 detik & menyala & 4 detik & 0 & danger \\
\hline 10 & api 5 detik & menyala & 5 detik & 0 & danger \\
\hline 11 & api 6 detik & menyala & 6 detik & 0 & danger \\
\hline 12 & api 7 detik & menyala & 7 detik & 0 & danger \\
\hline 13 & api 8 detik & menyala & 8 detik & 0 & danger \\
\hline 14 & api 9 detik & menyala & 9 detik & 0 & danger \\
\hline 15 & api 10 detik & menyala & 10 detik & 0 & danger \\
\hline
\end{tabular}

\subsubsection{Pengujian sensor Suhu}

Pengujian sensor suhu dilakukan untuk melihat sensitifitas sensor dalam mendeteksi perubahan suhu ruangan yang berada disekitar sensor. Hasil data dari pengukuran suhu akan ditampilkan melalui serial monitor pada Arduino perangkat lunakberupa jumlah suhu yang ada pada box panel listrik. Dalam pengujian sensor suhu menggunakan Arduino Atmega328, sensor suhu (DHT22) buzzer dan LED sebagai indikator untuk melihat perubahan kondisi buzzer dan LED pada saat suhu berada pada batas maksimal maupun melebihi batas maksimal.
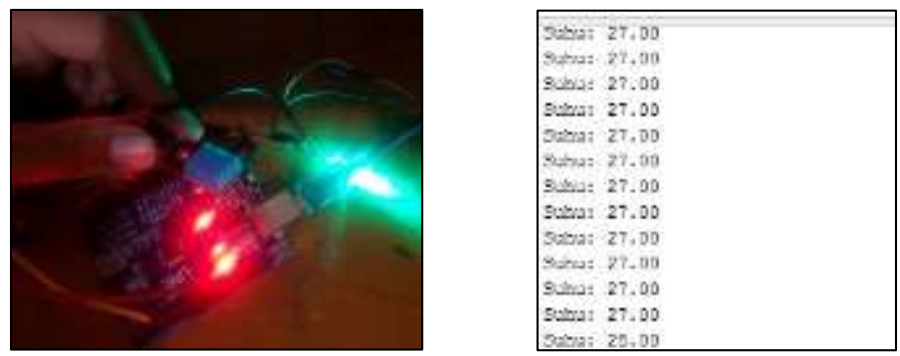

Gambar 13. Pengujian sensor suhukondisi normal

Gambar 13 memperlihatkan pengujian sensor suhu dalam kondisi normal yaitu nilai yang didapatkan berada dibawah $31^{\circ} \mathrm{C}$, dimana buzzer dan LED tidak hidup.

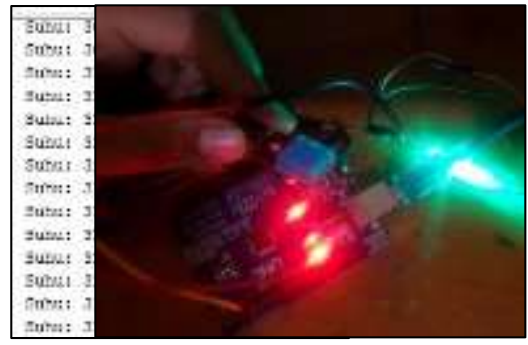

Gambar 12. Pengujian Sensor suhumelebihibatasmaksimal

Pada gambar 12 dilakukan pengujian sensor suhu pada saat mendeteksi suhu berada dibatas maksimal atau melebihi batas maksimal yaitu melebihi $31^{\circ} \mathrm{C}$, dimana buzzer akan berbunyi dan LED akan menyala untuk menandakan suhu melebihi batas maksimal yang sudah ditentukan. 
Tabel 2. Hasil Pengujian sensor suhu

\begin{tabular}{|c|c|c|}
\hline No & Sensor Suhu & Kondisi Buzzer dan LED \\
\hline 1 & $26^{\circ} \mathrm{C}$ & padam \\
\hline 2 & $27{ }^{\circ} \mathrm{C}$ & padam \\
\hline 3 & $28{ }^{\circ} \mathrm{C}$ & padam \\
\hline 4 & $29{ }^{\circ} \mathrm{C}$ & padam \\
\hline 5 & $30{ }^{\circ} \mathrm{C}$ & padam \\
\hline 6 & $31{ }^{\circ} \mathrm{C}$ & menyala \\
\hline 7 & $32{ }^{\circ} \mathrm{C}$ & menyala \\
\hline 8 & $33^{\circ} \mathrm{C}$ & menyala \\
\hline 9 & $34{ }^{\circ} \mathrm{C}$ & menyala \\
\hline 10 & $35{ }^{\circ} \mathrm{C}$ & menyala \\
\hline 11 & $36{ }^{\circ} \mathrm{C}$ & menyala \\
\hline 12 & $37^{\circ} \mathrm{C}$ & menyala \\
\hline 13 & $38{ }^{\circ} \mathrm{C}$ & menyala \\
\hline 14 & $39{ }^{\circ} \mathrm{C}$ & menyala \\
\hline 15 & $40 \quad{ }^{\circ} \mathrm{C}$ & menyala \\
\hline
\end{tabular}

\subsubsection{Pengujian Buzzer}

Pengujian dilakukan dengan mengaktifkan pin 13 pada Arduino Atmega 328 untuk mengaktifkan buzzer dengan indikator berupa lampu LED warna hijau. Buzzer digunakan untuk memberikan alarm tanda bahaya ketika sensor api dan suhu mendeteksi obyek keberadaan api dan suhu yang melebihi batas.

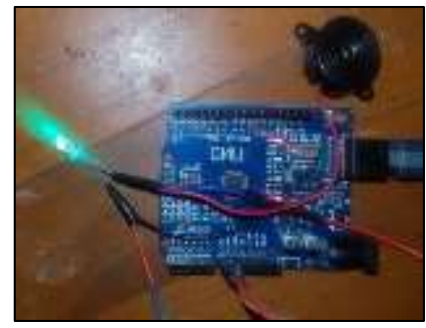

Gambar 14. Pengujian Buzzer

Pada gambar 30 menunjukkan buzzer dan LED aktif ketika pin 13 Arduino Atmega 328 diprogram untuk memberikan tegangan kepada buzzer dan LED sehingga menghasilkan bunyi dan LED menyala, Buzzer dan LED berfungsi dengan baik. Dari hasil pengujian dilakukan suatu pengukuran tegangan pada saat buzzer dan LED ketika menyala dan padam, hasil pengujian tersebut dituliskan pada tabel 5 sebagai berikut : Tabel 3. Hasil pengujian buzzer

\begin{tabular}{|c|c|c|}
\hline No. & Kondisi Buzzer dan LED & Volt \\
\hline 1 & Padam & 0 \\
\hline 2 & Menyala & 4,95 \\
\hline
\end{tabular}

\section{Hasil Uji Rancangan}

Sensor api yang digunakan memiliki sensitifitas yang tinggi dalam mendeteksi obyek api pada miniatur box panel kontrol listrik. Serta sensor suhu yang sensitif dalam mendeteksi suhu yang berada pada box panel tersebut. Sensor mendeteksi obyek api maupun perubahan suhu dan menampilkan data melalui aplikasi Arduino IDE dan memberikan status kondisi keadaan box panel. Bila suhu berada dibatas maksimal 
ataupun dibawah batas maksimal yang sudah ditentukan dan sensor api tidak mendeteksi adanya obyek api maka status pada visual basic akan normal.

RancangBangun Detector Kebakaran Panel Listrik Berbasis Microcontroller Atmega328

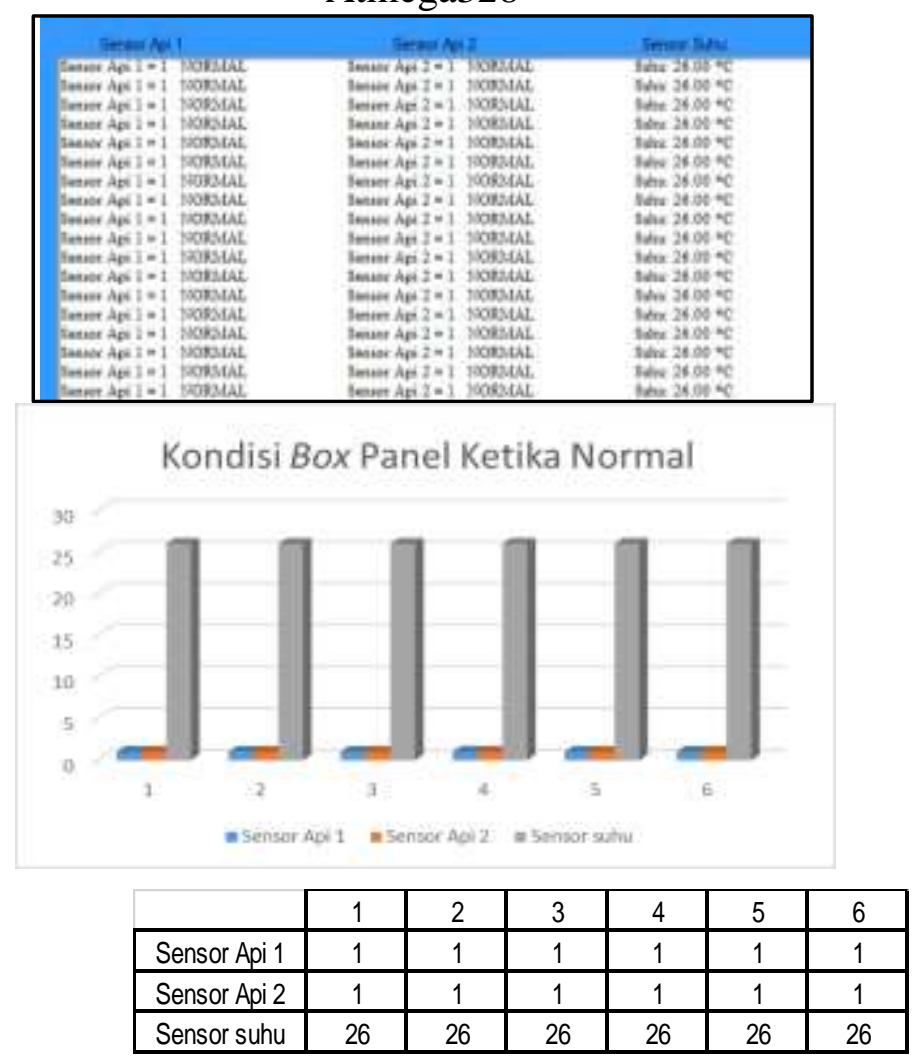

Gambar 15.Grafikkondisi box panel normal

Gambar diatas adalah pengujian pada saat sensor suhu berada dibatas maksinal dan sensor api 1 dan 2 tidak mendeteksi adanya obyek api yang berada pada box panel kontrol listrik, maka status kondisi dalam keadaan normal indikator buzzer dan LED tidak berbunyi.

RancangBangun Detector Kebakaran Panel Listrik Berbasis Microcontroller Atmega328

\begin{tabular}{|c|c|c|}
\hline Sesorktal & Sers $4 x 2$ & Seranghy \\
\hline 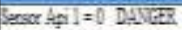 & 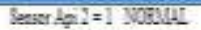 & $\sec 2700=C$ \\
\hline lenor $\operatorname{Apl} 1=0$. DHVER & 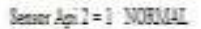 & $\operatorname{sect} 2700=c$ \\
\hline 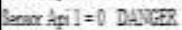 & 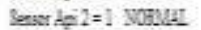 & sith 27000 \\
\hline 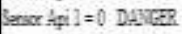 & Seasr $d$ q $2=1$ voruL & $3 \mathrm{ces} 23000^{\circ} \mathrm{C}$ \\
\hline Sensor Afi $1=0$ DUVGEX & Seaver $k=1=1$ vosuut & $\sec 2 c^{2} \mathrm{C}$ \\
\hline 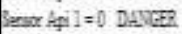 & Senar del = I NDEULI & $\operatorname{sech} 23100=c$ \\
\hline Eararkil $=0$ DAYGez & Sener $d$ sin = I JOBMUI & $\operatorname{sen} 2300+c$ \\
\hline 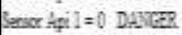 & 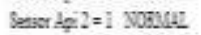 & $3 \mathrm{cht}=28000^{2} \mathrm{C}$ \\
\hline Serser Agil $=0$ DHVIEE & Senser 1 - I = I vobut & $\sec 2 \sec =\mathrm{C}$ \\
\hline 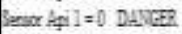 & 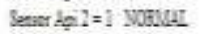 & $\operatorname{set} 2300=c$ \\
\hline 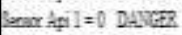 & 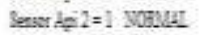 & $\operatorname{cit}=2800=$ \\
\hline
\end{tabular}

Gambar 16. Kondisi box panel ketika salah satu sensor mendeteksi objek 


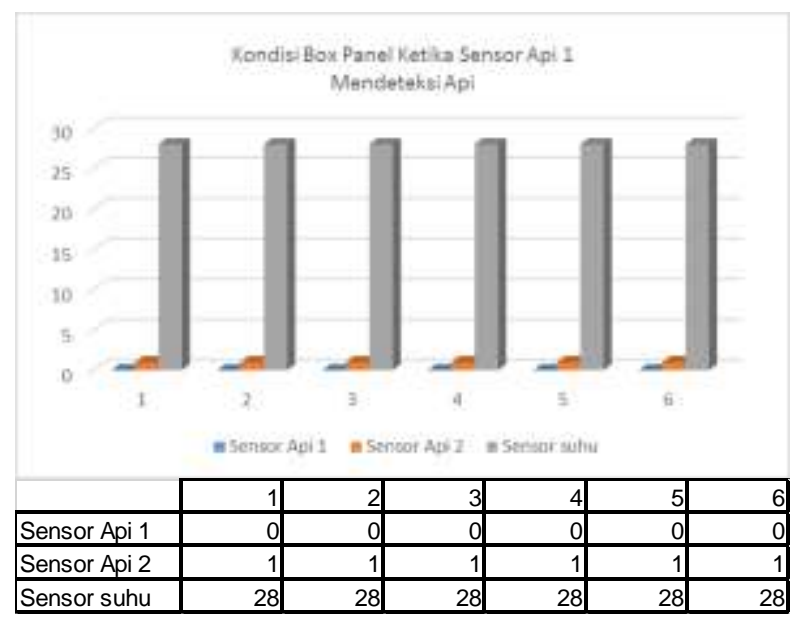

Gambar 17. Grafik box panel ketika salah satu sensor mendeteksiobjek

Gambar diatas adalah pengujian pada saat sensor api 1 mendeteksi adanya obyek api sedangkan sensor api 2 tidak mendeteksi adanya obyek api pada box panel kontrol listrik. Status yang ditampilkan pada sensor api 1 dalam kondisi danger. Nilai yang di dapatkan oleh sensor suhu berupa nilai temperatur $\left({ }^{0} \mathrm{C}\right)$, kemudian indikator buzzer dan LED akan menyala sebagai informasi tanda bahaya.

RancangBangun Detector Kebakaran Panel Listrik Berbasis Microcontroller Atmega328

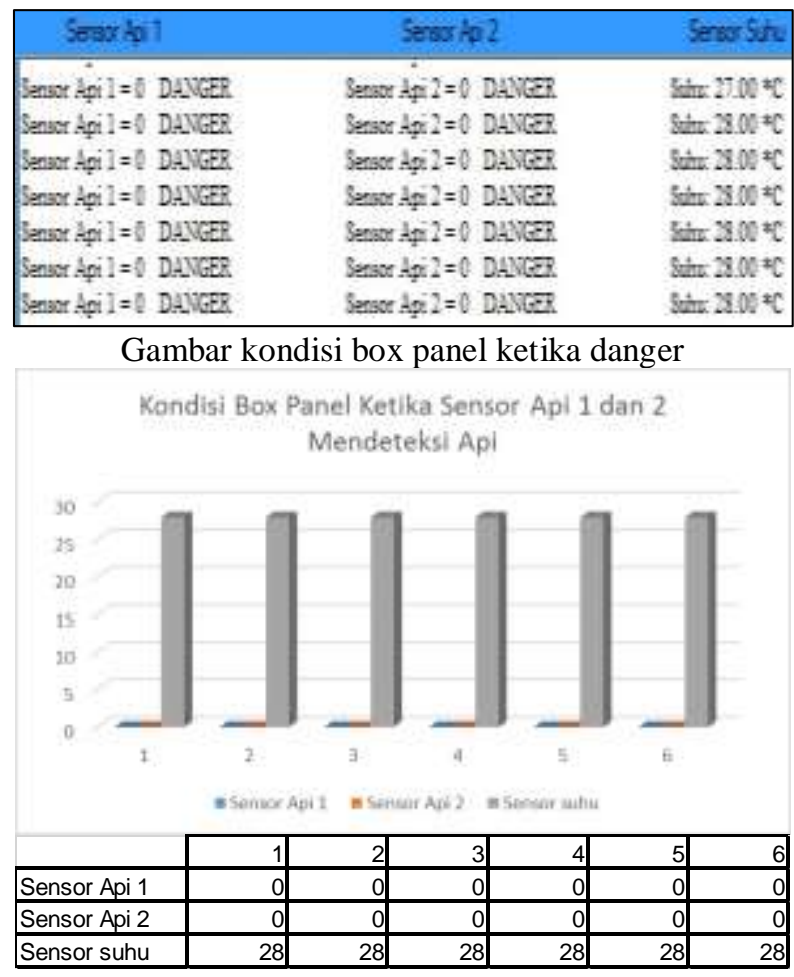

Gambar 18.Grafikkondisi box panel denger

Gambar diatas adalah hasil pengujian pada saat box panel kontrol listrik dalam kondisi danger, kedua sensor api mendeteksi adanya obyek api yang ada pada box panel, indikator buzzer dan LED akan menyala untuk memberikan informasi tanda bahaya. 


\section{KESIMPULAN DAN SARAN}

\section{Kesimpulan}

Berdasarkan hasil rancang bangun dan uji coba alat deteksi kebocoran refrigeran, maka dapat disimpulkan sebagai berikut :

1. Telah dibuat Rancang Bangun Detector Kebakaran Panel Listrik Berbasis MicrocontrollerAtmega328 sesuai dengan rancangan awal yaitu alat yang dirancang berhasil mendeteksi api dan suhu yang melebihi batas maksimal pada box panel kontrol listrik di kapal, ketika sensor mendeteksi api atau suhu yang melebihi batas maksimal buzzer dan LED akan menyala untuk menginformasikan tanda bahaya.

2. Monitoring Prototipe ditampilkan melalui Sofware Arduino IDE dalam sinyal digital 1 dan 0 , nilai suhu dalam ${ }^{\circ} \mathrm{C}$ dan status box Panel listrik. Data yang ditampilkan pada Sofware Arduino IDE di update setiap detik agar dapat dimonitor setiap waktu.Secara keseluruhan dapat diartikan bahwa Rancangan dapat bekerja dengan baik sesuai apa yang telah diharapkan.

\section{Saran}

Berdasarkan hasil dan pembahasan, maka saran yang penulis sampaikan adalah sebagai berikut:

1. Monitoring Prototipe ditampilkan melalui Sofware Arduino IDE dalam sinyal digital 1 dan 0 , nilai suhu dalam ${ }^{\circ} \mathrm{C}$ dan status box Panel listrik. Data yang ditampilkan pada Sofware Arduino IDE di update setiap detik agar dapat dimonitor setiap waktu.Secara keseluruhan dapat diartikan bahwa Rancangan dapat bekerja dengan baik sesuai apa yang telah diharapkan.

2. supaya rangkaian yang digunakan tidak terganggu, sebaiknya alat ini dikemas dalam bentuk yang lebih aman dan terlindungi, sehingga penggunaanya lebih efektif.

3. Diharapkan pada penelitian selanjutnya prototipe ini dapat dikembangkan dengan menggunakan sensor lain seperti Sensor MQ2, sedangkan Microcontroller dapat menggunakan Arduino Mega,Due, Nano maupun yang mini dan mikro yang ukurannya lebih kecil.

\section{DAFTAR PUSTAKA}

Banzi, M. 2008. Gettting Started with Arduino. O’Reilly. Sebastopol. 110 Hal.

Budi Setiyo.2014. Korsleting Listrik Penyebab Kebakaran Pada Rumah Tinggal Atau Gedung. Edu Elektrika Journal, Vol 3 No 2.

Dani, P. 2016. 30 Arduino Tutorials Projects Smart Arduino.

Fikriyah, L., \& Rohmanu, A. 2018. Sistem Kontrol Pendingin Ruangan Menggunakan Arduino Web Server dan Embedded Fuzzy Logic di PT. Inoac Polytechno Indonesia. Jurnal Informatika SIMANTIK Vol. 3 No. 1. 
Gessal, C.I.Y,. Dkk. 2019. Kolaborasi Aplikasi Android Dengan Sensor MQ-135 Melahirkan Detektor Polutan Udara. Jurnal Teknik Informatika vol 14 no. 1.

Lilik Hari Santoso , Siti Roudhotul Hasanah . 2017. Rancang Bangun Sistem Alarm Kebakaran Otomatis Berbasis Arduino Uno Menggunakan Sensor Cahaya dan sensor Gas di Teaching Factory STT Texmaco Subang. Teknik Elektro, Sekolah Tinggi Teknologi Texmaco. Jurnal TrendTech Volume-2/Nomor-3, 2017

Mandarani, P. 2014. Perancangan dan Implementasi User Interface Berbasis Web Untuk Monitoring Suhu, Kelembaban dan Asap pada Ruangan Berbeda dengan Memanfaatkan Jaringan Local Area Network. Jurnal TEKNOIF, Vol. 2 No. 2.

Marselinus, M. 2012 . Sistem Alarm Kebakaran Menggunakan Infrared dan Sensor Suhu berbasis Arduino Uno : Jurusan Fisika, Fakultas Sains dan Teknik ,Universitas Nusa Cendana.

Maulidin, M. S., Dkk. 2016. MQ - 2 Sebagai Sensor Anti Asap Rokok Berbasis Arduino Dan Bahasa C.Fakultas Teknik Universitas Wahid Hasyim Semarang.

Nurfiana, \& Hasbiyantoro, W. 2017. Implementasi Sistem Monitoring Asap Rokok Melalui Smartphone Menggunakan Sensor Mq-135 Berbasis Arduino Untuk Meningkatkan Gerakan Displin Kampus (Gdk). Jurnal Sistem Informasi dan Telematika.Volume 8, Nomor 1.

Putra, F. M., Kridalaksana, A. H., \& Arifin, Z. 2017. Rancang Bangun Alat Pendeteksi Kebocoran Gas Lpg Dengan Sensor Mq-6 Berbasis Mikrokontroler Melalui Smartphone Android Sebagai Media Informasi. Jurnal Informatika Mulawarman, Vol. 12, No. 1.

Refky Armando, dan Rozeff P. 2015. Prototipe Pendeteksi Suhu pada box Panel Listrik : Universitas Maritim Raja Ali Haji Tanjung Pinang. Jurnal Ilmiah Teknik Industri Vol. 14.

Sasmoko, D., \& Mahendra, A. 2017. Rancang Bangun Sistem Pendeteksi Kebakaran Berbasis IOT dan Sms Gateway Menggunakan Arduino. Jurnal SIMETRIS, Vol 8 No 2.

Setyowinoto dan Indra Gunawan . 2017. Robot Pemadam Api Menggunakan Sensor Ultrasonic dan Flame Sensor Berbasis Mikrokontroler Arduino Uno. Teknik Elektro, Sekolah Tinggi Teknologi Texmaco. Jurnal TrendTech Volume2/Nomor-3, 2017

Supegina. F., Wahyudi. 2013. Rancang Bangun Sistem Alarm Dan Pintu Otomatis Dengan Sensor Gas Berbasis Arduino. Jurnal Teknologi Elektro, Vol.4 No.2.

Susiono. 2010. Model Instalasi Listrik Yang Dapat Mencegah Bahaya Kebakaran Pada Bangunan. Teknologi Elektro Vol. 91 No.1. 
Yulianti, D. I., Lestari, K. D., \& Novenpa N. N. 2018. Papan Informasi Digital Kandungan Gas Menggunakan Mega Kit Sensor (Mq-7, Dht-22,Mq-135) sebagai Indikator Kualitas Udara di Lingkungan FMIPA UNESA. FMIPA.Universitas Negeri Surabaya 